\title{
Therapeutic Gonadotropin
}

National Cancer Institute

\section{Source}

National Cancer Institute. Therapeutic Gonadotropin. NCI Thesaurus. Code C527.

A class of formulated therapeutic analogs of the endogenous gonadotropin that stimulates or promotes the function of the gonads. Therapeutic gonadotropins are derived from animal or recombinant sources. Gonadotropins include follicle-stimulating hormone, luteinizing hormone and chorionic gonadotropin. These agents stimulate discrete cellular components of the gonads, exerting effects in both males and females. $(\mathrm{NCl04})$ 